\title{
Antarctic clouds
}

\author{
Tom Lachlan-Cope
}

British Antarctic Survey, High Cross, Madingley Road, Cambridge, Cambridgeshire CB3 OET, UK. E-mail: tlc@bas.ac.uk

Keywords

Antarctic; clouds; mixed phase.

doi:10.1111/j.1751-8369.2010.00148.x

\begin{abstract}
Sensitivity studies with global climate models show that, by their influence on the radiation balance, Antarctic clouds play a major role in the climate system, both directly at high southern latitudes and indirectly globally, as the local circulation changes lead to global teleconnections. Unfortunately, observations of cloud distribution in the Antarctic are limited and often of low quality because of the practical difficulty in observing clouds in the harsh Antarctic environment. The best surface observations suggest that the fractional cloud cover at the South Pole is around $50-60 \%$ in all seasons, whereas the cloud cover rises to around $80-90 \%$ close to the coast of the continent. Microphysical observations of cloud parameters are also very sparse in the Antarctic. However, the few measurements that do exist show predominantly ice-crystal clouds across the interior, with mixed-phase clouds close to the coasts. Crystal sizes vary from 5 to $30 \mu \mathrm{m}$ (effective radius) in the interior to somewhat larger ice crystals and water drops near the coast. A wide range of crystal shapes is observed at all sites. This review considers the available cloud observations and highlights the importance of Antarctic clouds and the need for better observations in the future.
\end{abstract}

Clouds are an important part of the global climate system. For example, the fourth assessment report issued by the Intergovernmental Panel on Climate Change (IPCC) noted that the indirect effect of aerosols on clouds is a relatively large negative radiative forcing of $-0.7 \mathrm{Wm}^{-2}$, but that the range of uncertainty in this value is large and the level of scientific understanding is "low" (IPCC 2007: fig. SPM2). The feedbacks associated with clouds, and whether clouds act to warm or cool the atmosphere, are complex, and are not properly understood even at mid-latitudes where they have been observed in detail for many years. In the Antarctic, cloud observations have largely been confined to synoptic observations, although in recent years these measurements have been supplemented by occasional in situ microphysical measurements, mainly of low cloud from the surface, and radiometric measurements made from the surface and from satellite data. These measurements have only been made at a few locations - the South Pole and some coastal stations-and these locations may not be representative of the continent as a whole.

The microphysical properties (shape, size, concentration and phase, i.e., whether solid or liquid) of cloud particles can have a major impact on the Earth's radiation budget, so it is important that they are correctly represented within climate models. However, the parameterizations of clouds used in global climate models have normally been developed using measurements made in mid-latitudes, and these may not be applicable to Antarctic clouds. Again, because of the isolated and harsh environment of the continent few in situ measurements have been of the microphysical properties of clouds in the Antarctic.

This review of Antarctic clouds first looks at the basic measurements of cloud cover taken visually by observers and from satellite measurements. Later, more detailed microphysical measurements are considered before finally discussing the impact of clouds on the radiation balance and climate of Antarctica.

\section{Cloud cover}

Figure 1 shows a composite infrared satellite image of the Antarctic continent and the surrounding oceans. The most noticeable features are the frontal cloud bands associated with large, mid-latitude depressions that circle the Antarctic continent. The clouds associated with these frontal systems tend to be deep, and so the cloud tops are 
Fig. 1 Infrared Antarctic cloud composite image for 29 September 2008. (Image provided by, and used with permission of, the Antarctic Meteorological Research Center, University of Wisconsin-Madison.)

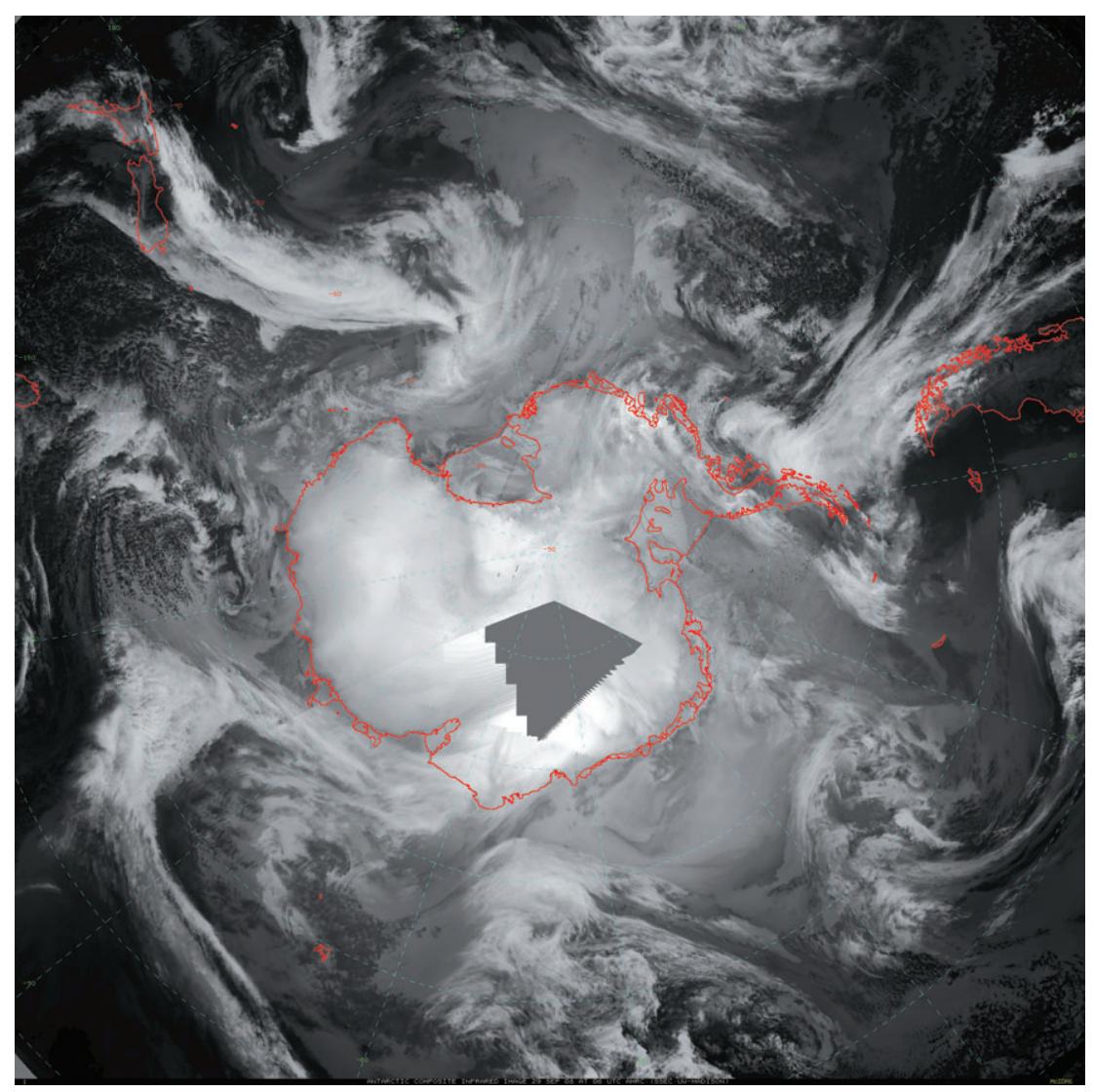

high and cold, and show up as white in the infrared image. Between the high frontal cloud bands large areas of uniform low stratus, or sea ice, can be seen close to and encircling the continent. It is difficult to distinguish between low cloud and sea ice in satellite imagery. However, it is likely that most of the large areas of uniform cover surrounding the continent are clouds. Away from the continent the stratus tends to break down into convective cumulus cells. An interesting feature seen in the clouds in this composite are the two mesoscale cyclones (or polar lows; see Rasmussen \& Turner 2004) around $120^{\circ}$ and $150^{\circ} \mathrm{E}$ : these small cyclones are common at high latitudes, particularly where there is a large sea-air temperature difference. Moving over the continent it becomes more difficult to distinguish between cloud and the underlying snow and ice surface, although in this image it appears that the high-level frontal cloud does not encroach very far onto the continent.

Although visual examination of satellite imagery gives us some insight into the distribution of clouds over Antarctica, for most investigations it is necessary to have some objective measure of the clouds. Several different objective methods have been used to measure cloud cover in the Antarctic. These range from ground-based visual observations to space-borne passive instruments, such as those used to obtain Fig. 1, and active measurements such as light detection and ranging (LIDAR). These methods can give quite different results, and it can be difficult to establish the true value of the extent and frequency of cloud.

Surface visual observations have been routinely made at Antarctic research stations for the last 50 years, and give the longest running cloud data set available (Hahn \& Warren 2003). However, the surface observing sites are widely spaced in Antarctica, and most are located close to the coast. There have been many changes to the surface observational record, as sites have changed location, and there have been modifications to the observing practice. Visual observations are, by their very nature, subjective, and changes in observer can result in step changes in particular measurements. This can decrease their value when looking for long-term trends. Also, visual observations during the night are difficult to make because of the low level of illumination of the clouds (Hahn et al. 1995), and this is particularly true of Antarctic clouds during the winter. Figure 2 shows the annual cycle of fractional cloud cover at the South Pole from visual observations. 


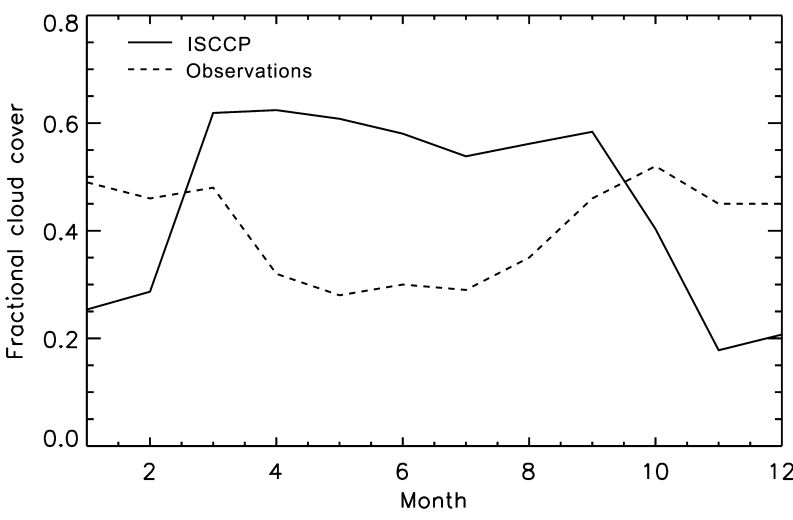

Fig. 2 Monthly fractional cloud cover at the South Pole from International Satellite Cloud Climatology Project (ISCCP) satellite retrievals and surface visual observations, using data from the ISCCP and from Hahn \& Warren (2003).

This indicates a decrease in cloud cover during the winter, when the clouds are difficult to observe, compared with the summer months.

Surface radiation measurements can also be used to derive cloud cover. Town et al. (2007) compared fractional cloud cover from visual observations, satellite retrievals and surface-based infrared measurements at the South Pole. They suggested that the best measurements are those retrieved from surface-based pyrgeometer measurements, both in terms of accuracy and length of record, as they are not affected by the lack of sunlight. Town et al. (2007: fig. 6) compared surface visual observations with values retrieved from the pyrgeometer, and showed that during summer the two values agree well, whereas during winter the visual observations are around 20\% lower. The pyrgeometer values suggest that the cloud cover at the South Pole is constant throughout the year, at around 50-60\%.

Surface measurements are limited spatially, especially in data-sparse regions such as Antarctica. Passive satellite instruments measure the upwelling radiation emitted from the surface or atmosphere, and measurements taken using such instruments have a much better spatial coverage. With passive measurements it can be difficult to distinguish between the clouds and the underlying snow surface, as the temperature and radiative properties of the cloud and snow surface are similar. However, there have been several attempts to retrieve cloud cover from the US National Oceanic and Atmospheric Administration (NOAA) series of polar orbiting satellites that measure in the visual and infrared bands, most notably the International Satellite Cloud Climatology Project (ISCCP) (see Rossow \& Schiffer 1999; Hatzianastassiou et al. 2001). These cloud retrievals are compared with surface observations in Fig. 2, where it can be seen that the satellite
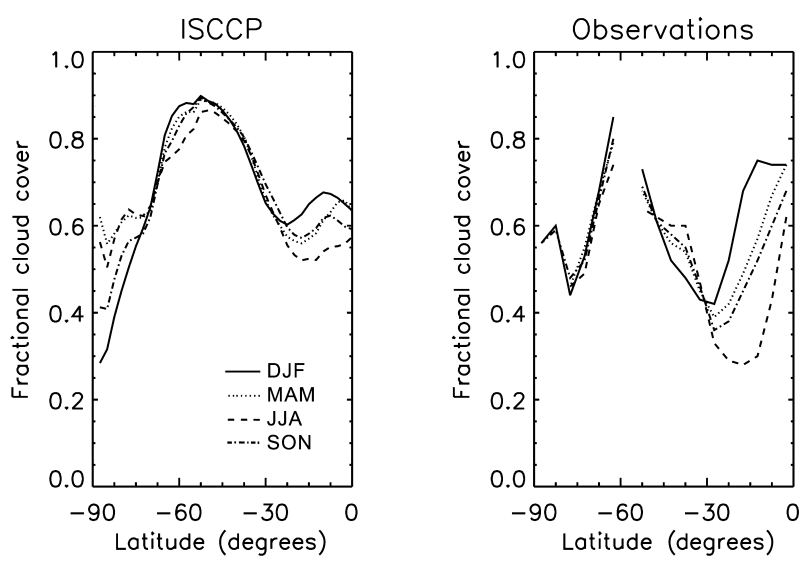

Fig. 3 Zonally averaged total cloud cover from the International Satellite Cloud Climatology Project (ISCCP) and surface observations for four seasons, using data from the ISCCP and from Hahn \& Warren (2003).

clouds levels are less than the surface observations during the summer, but are more during the winter. Another set of retrievals using NOAA satellite data are the Extended Advanced Very High Resolution Radiometer (AVHRR) Polar Pathfinder (APP-x) data set (see Town et al. 2007; Wang \& Key 2005), which concentrate on the polar regions. Town et al. (2007) compared both the ISCCP and the APP-x retrievals with surface-based estimations of cloud cover, from infrared radiometers (pygreometers), at the South Pole. They found that during the summer the APP-x cloud cover was slightly higher than the pygreometer values, whereas the ISCCP estimates were too low (by around 30-40\%).

As well as comparing the cloud cover derived by several different methods, it is interesting to look at the variation of cloud cover with latitude. Figure 3 shows the variation with latitude for both ISCCP retrievals of cloud fraction and surface observations, and it can be seen that cloud cover is at a minimum in the centre of the continent, and increases to a maximum close to the coast, a result that compares well with the subjective impression gained from Fig. 1.

More recent active satellite-borne instruments, such as lasers (Spinhirne et al. 2005), are able to distinguish clouds over a snow and ice surface more easily, but as yet the records from these instruments are short. Spinhirne et al. (2005) report values of cloud cover for the month of October 2003 from the Geoscience Laser Altimeter System (GLAS) instrument carried on the Ice, Cloud, and land Elevation Satellite (ICESat). Although these measurements are limited they do show the same variation in cloud fraction with latitude as the satellite and surface observations (Spinhirne et al. 2005: fig. 4), with an increase from the pole towards the coast. 


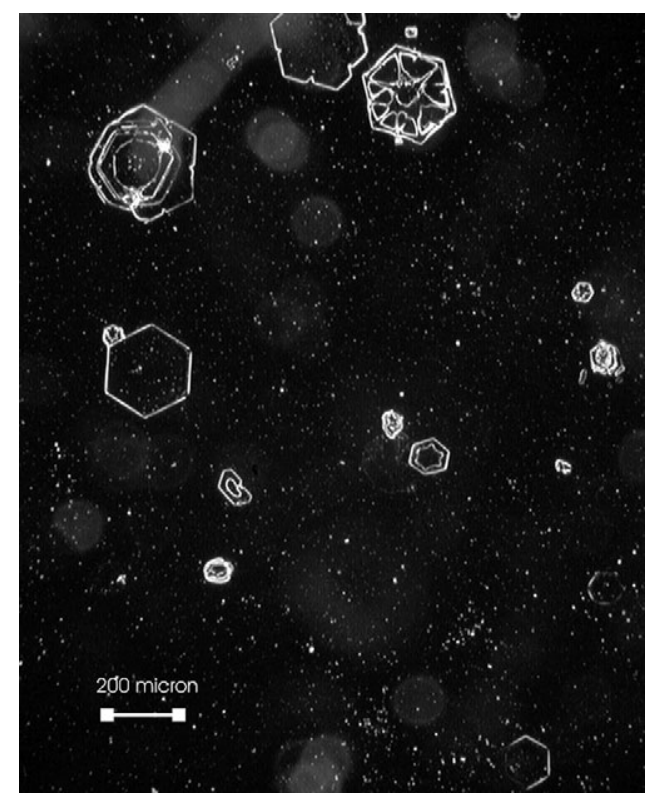

Fig. 4 Photomicrograph of Formvar replicas of cloud particles. The particles were collected on the Avery Plateau at 15:07z on 4 December 1995.

\section{Cloud microphysical properties}

Measuring cloud microphysical properties, such a particle size, whether solid or liquid (phase) and crystal shape (habit), is, of course, difficult in the extreme Antarctic environment. This means less is known about the microphysics of Antarctic clouds than of mid-latitude clouds. However, some measurements have been made in Antarctica using both remote sensing techniques and occasionally in situ methods. Several groups have used LIDAR to investigate cloud properties using ground-based instruments (Smiley et al. 1977; Smiley 1980; Smiley et al. 1980; Del Guasta et al. 1993) and airborne instruments (Morley et al. 1989). Other groups have used radiation measurements to infer microphysical properties, which include using ground-based interferometers (Mahesh et al. 2001a, b) and balloon-borne radiometers (Stone 1993). Another approach is to measure the microphysical properties directly, either by the in situ collection of cloud particle replicas from the clouds that reach down to the surface (Ohtake 1978; Lachlan-Cope et al. 2001; Walden et al. 2003, Hogan 1975; Lawson et al. 2006) or from in situ aircraft measurements (Saxena \& Ruggiero 1990).

The flights made by Morley et al. (1989) with an airborne LIDAR clearly showed the difference between the clouds found near the coast and those over the high plateau. On flights from McMurdo Station to the South Pole and Siple stations, an abrupt change in cloud type was seen as the plane passed from the low-lying Ross Ice
Shelf to the higher level polar plateau. The dense midlayer water clouds found over the Ross Ice Shelf were replaced by higher ice clouds, predominantly cirrus. These flights were carried out on one day during January 1986, and so are limited in scope. The LIDAR used by Morley et al. (1989) could not measure polarization, and so they had to infer the phase of the cloud. However, their results can be compared with the more comprehensive measurements made at the South Pole and at a coastal station (Dumont d'Urville) with more advanced ground-based LIDAR.

Del Guasta et al. (1993) operated a depolarization backscattering LIDAR at Dumont d'Urville station during 1989 and 1990. This instrument did not measure clouds lower than $500 \mathrm{~m}$ and did not give reliable results for thick clouds, and so their results are biased towards thin, high clouds. Given this bias, it is not surprising that they do not seem to have observed any clouds composed solely of water droplets. At temperatures below -25 to $-30^{\circ} \mathrm{C}$ the clouds are predominately ice clouds made up of columnar ice crystals or small ice particles. At temperatures above -25 to $-30^{\circ} \mathrm{C}$ mixed phase clouds are frequently recognized, associated with ice-precipitating mid-level clouds.

During the austral winter of 1975, Smiley et al. (1980) operated a LIDAR at the South Pole. This instrument was not as advanced as the one used by Del Guasta et al. (1993), and did not give any information on polarization. However, at the South Pole during winter the temperature is such that it can be assumed that most of the clouds observed are ice crystal clouds. This was confirmed by Formvar replicas taken at the surface at the same time. Smiley often observed low-lying precipitation with higher formation layers.

The LIDAR measurements do not give information on particle size, and there are no aircraft in situ measurements of size in Antarctica, except for a limited study by Saxena \& Ruggiero (1990), who measured particle size over the Ross Ice Shelf using a Forward Scattering Spectrometer Probe during two flights. However, most information on particle size, and habit, comes from radiometer measurements, both surface-based interferometer and radiometer sondes.

Radiometer sondes were flown at the South Pole in the austral winter months between 1959 and 1963 as part of the US Weather Bureau's Polar Operations Project. The data from these flights, consisting of vertical profiles of upward and downward longwave irradiances, were not analysed until Stone used them to calculate the properties (emissivity, optical depth and effective radius) of winter clouds (Stone 1993). This data set was fairly limited, and after strict quality control criteria were applied to the data only eight flights were left during overcast conditions. He 
found that generally the cloud base coincided with the top of the surface-based inversion level, which was at a height of $465 \mathrm{~m}$ above surface. He found that the clouds he investigated were quite thin, with an effective broadband infrared optical depth of around 1 and longwave emissivity of 0.62 . The effective radius of the ice particle was found to be between 4 and $16 \mu \mathrm{m}$.

Mahesh et al. (2001a) used a Fourier-transform interferometer to derive cloud parameters at the South Pole during 1992. These parameters included cloud-base heights, and although the data set was again somewhat limited, with measurements having only been taken at 1030 and 2230 UTC, it does provide a much larger data set than that of Stone. Mahesh reported a bimodal distribution in cloud height, with values either above or below the inversion height, which does not agree with Stone's rather more limited data set. However, the clouds were rather thin, and it is likely that the uncertainties in both methods are relatively large. Mahesh also derived optical depths and particle sizes (Mahesh et al. 2001b), and these agreed with those found by Stone (1993), with the optical depths being generally less than 1.0 and the particle radii during the winter being generally below $25 \mu \mathrm{m}$. Ricchiazzi et al. (1995) used a multichannel radiometer based at Palmer Station $\left(64^{\circ} 46^{\prime} \mathrm{S}, 64^{\circ} 04^{\prime} \mathrm{W}\right)$ to calculate cloud optical depths during the spring of 1991. The optical depths that they obtained at this coastal station were much larger than those obtained by Mahesh et al. (2001a) at South Pole Station, and ranged between 20 and $50 \mu \mathrm{m}$ with a most probable value of $25 \mu \mathrm{m}$.

In the interior of Antarctica and on the high plateau on top of the Antarctic Peninsula, ice crystals are often observed in the atmosphere close to the surface, and are coded in routine surface observations as diamond dust, which is also known as precipitation from a clear sky. These particles are often larger than cloud particles, and range in radius at the South Pole from 2 to $1000 \mu \mathrm{m}$ (Walden et al. 2003). The larger particles have a significant fall speed, depending on their shape, and they can make up a significant part of the accumulation. The formation and development of these crystals is very interesting and important both for the surface mass balance and the radiation balance over the Antarctic Plateau. Several attempts have been made to observe and measure these ice crystals close to the surface. Hogan (1975), Ohtake (1978), Lachlan-Cope et al. (2001) and, most recently, Walden et al. (2003) have all collected crystals at the surface, and either photographed them directly or made replicas of them using the Formvar technique (Takahashi \& Fukata 1988). Both Hogan and Ohtake collected somewhat limited data sets during the summer. However, Walden collected a much larger data set comprising the dimensions of about 20000 crystals during the Antarctic winter of 1992. The predominant types of crystals observed were diamond dust in the form of columns (hexagonal prisms) or hexagonal plates. He also observed blowing snow particles and snow grains precipitating from clouds. Figure 4 shows a microphotograph of hexagonal plates collected on the Avery Plateau; this image was used by Lachlan-Cope et al. (2001) in their study of clouds over the Antarctic Peninsula. Occasionally, very long crystals were observed that were $1000 \mu \mathrm{m}$ in length but only $10 \mu \mathrm{m}$ in width. Such crystals are known as Shimizu crystals (Shimizu 1963). Kikuchi \& Hogan (1979) looked at the variation of width to length of the crystals observed on one day in 1975, and found that the columnar type prevailed, and that the ratio of length to width varied cyclically with a period of around $2 \mathrm{~h}$, although they offered no explanation for this observation. Walden calculated the effective radius of the entire size distribution of the diamond dust to be around $12 \mu \mathrm{m}$, and this agrees well with the effective radius inferred from radiation measurements at the South Pole (see above). Walden found diamond dust in the form of both plates and columns at temperatures below $-40^{\circ} \mathrm{C}$, supporting the laboratory results of Bacon et al. (2003), which showed that factors other than humidity and temperature are important in determining the habit of a crystal. As well as measuring diamond dust, Walden et al. (2003) collected blowing snow particles and snow grains. The blowing snow particles are lifted from the surface when the wind speed is greater than about $7 \mathrm{~m} \mathrm{~s}^{-1}$, a process that is often assisted by saltation-when a precipitating particle dislodges one or more particles from the surface. This process means that the blowing snow particles tend to have undergone several collisions, and tend to be rounded, and so are easily distinguished from the more regular diamond dust crystals. It is interesting to note that Walden et al. (2003) found particles that appeared to be the same shape as blowing snow particles on days when the average wind speed was less than $7 \mathrm{~m} \mathrm{~s}^{-1}$ and when the weather observers did not report any blowing snow. They interpreted these crystals as residual blowing snow crystals that continued to settle for day or two after the wind speed had dropped. It is interesting that blowing snow particles have such a long lifetime in the atmosphere, and it is possible that they play a further role as ice nuclei within clouds. The snow grains observed by Walden et al. (2003) were crystals precipitating from clouds, and tend to be made up of clusters of plates or bullet crystals, and are as such are easy to distinguish from the single diamond dust crystals.

More recently, advanced particle imagers of the sort developed for use in aeroplanes have been deployed at the South Pole (Lawson et al. 2006) during early February 2001. This instrument, known as a cloud particle 
Table 1 A summary of the cloud particle sizes measured at various locations in Antarctica.

\begin{tabular}{|c|c|c|c|c|c|}
\hline Where/who & When & Height & Size (mean) & Phase & Shape \\
\hline South Pole / Lawson et al. (2006) & February 2001 & surface & $\begin{array}{l}17 \mu \mathrm{m}\left(r_{\mathrm{va}}\right) \\
10.5 \mu \mathrm{m}\left(r_{\mathrm{va}}\right) \\
25.3 \mu \mathrm{m}\left(r_{\mathrm{va}}\right) \\
27.9 \mu \mathrm{m}\left(r_{\mathrm{va}}\right) \\
19.2 \mu \mathrm{m}\left(r_{\mathrm{va}}\right) \\
17.8 \mu \mathrm{m}\left(r_{\mathrm{va}}\right) \\
27.2 \mu \mathrm{m}\left(r_{\mathrm{va}}\right) \\
17.0 \mu \mathrm{m}\left(r_{\mathrm{va}}\right)\end{array}$ & ice & $\begin{array}{l}\text { diamond dust } \\
\text { column } \\
\text { budding } \\
\text { rosette } \\
\text { complex } \\
\text { plates } \\
\text { thick plates } \\
\text { rosette } \\
\text { blowing snow }\end{array}$ \\
\hline South Pole / Walden et al. (2003) & winter 1992 & surface & $\begin{array}{l}12.2 \mu \mathrm{m}\left(r_{\text {eff }}\right) \\
11.0 \mu \mathrm{m}\left(r_{\text {eff }}\right) \\
23.6 \mu \mathrm{m}\left(r_{\text {eff }}\right) \\
10.7 \mu \mathrm{m}\left(r_{\text {eff }}\right)\end{array}$ & ice & $\begin{array}{l}\text { diamond dust } \\
\text { blowing snow } \\
\text { snowgrains } \\
\text { all crystals }\end{array}$ \\
\hline $\begin{array}{l}\text { South Pole / Stone (1993) } \\
\text { South Pole / Mahesh et al. (2001b) }\end{array}$ & $\begin{array}{l}1959-1963 \\
1992\end{array}$ & $\begin{array}{l}140-840 \text { m a.s.l. } \\
\text { above surface }\end{array}$ & $\begin{array}{l}\text { 4-16 } \mu \mathrm{m}\left(r_{\text {eff }}\right) \\
15 \mu \mathrm{m}\left(r_{\text {eff }}\right)-\text { mode }\end{array}$ & $\begin{array}{l}\text { ice } \\
\text { ice }\end{array}$ & all crystals \\
\hline Byrd Station $\left(80^{\circ} \mathrm{S}, 120^{\circ} \mathrm{W}\right) /$ Shimizu (1963) & 1961 & surface & $1000 \mu \mathrm{m}$ (length) & ice & Shimizu crystal (long column) \\
\hline $\begin{array}{l}\text { Avery Plateau }\left(67^{\circ} \mathrm{S}, 65.5^{\circ} \mathrm{W}\right) / \text { Lachlan-Cope } \\
\text { et al. (2001) }\end{array}$ & 1995 & surface & $\begin{array}{l}20-200 \mu \mathrm{m} \\
10-50 \mu \mathrm{m}\end{array}$ & $\begin{array}{l}\text { ice } \\
\text { water }\end{array}$ & $\begin{array}{l}\text { all crystals } \\
\text { drops }\end{array}$ \\
\hline
\end{tabular}

imager (CPI), produces high-resolution images of cloud particles. These images mean that it is possible to investigate the habit of the crystals. In the Lawson et al. (2006) study, $30 \%$ of the particles were found to be rosette shaped, $45 \%$ were diamond dust (columns, thick plates and plates) and $25 \%$ had an irregular shape. This method measures the crystal radius directly, not an effective radius, and the distribution of maximum crystal size was found to have a peak that varied between 50 and $100 \mu \mathrm{m}$ (when looking at the number distributions). Converting the observed maximum dimension into an equivalent radius depends on both the volume and surface area. Lawson et al. (2006) used relationships to determine the volume and area from the parameters that can easily be measured from the CPI images. They found that the resulting equivalent radius was generally less than $50 \mu \mathrm{m}$, with a maximum in the size distribution around $25 \mu \mathrm{m}$. They did not calculate an effective radius, so it was not possible to compare these results directly with those obtained from the radiation measurements, although they were similar to measurements made by Walden et al. (2003). Lawson et al. (2006) reported that the crystals they observed at the South Pole appeared to be similar to those observed by the same instruments within cirrus clouds. They did observe blowing snow on at least one occasion, but did not have enough data to correlate the occurrences of blowing snow with the wind speed. Cloud particle sizes measured in Antarctica are summarized in Table 1.

Few measurements of cloud-forming nuclei have been made in Antarctica because of the difficulty in making the necessary measurements in remote areas. As the sources of such nuclei are likely to be limited, and possibly unique to the continent, it is very difficult to use results from other parts of the world. Even measurements in the Arctic are difficult to apply to the Antarctic, as proximity of snow-free land masses in the north mean that Arctic cloud-forming nuclei are likely to have a very different source. During 1994 Saxena (1996) measured cloud condensation nuclei at Palmer Station and at times found elevated concentrations. However, these were similar to results from the Arctic. Of course in the cold polar regions clouds are often composed solely of ice, or are of mixed phase, and so the availability of ice nuclei is important. Saxena \& Weintraub (1988) measured ice-forming nuclei at Palmer Station using a filter technique, and found ice nuclei concentrations that were similar to those measured elsewhere, although the values they reported did range over several orders of magnitude. Lachlan-Cope et al. (2001) have inferred the number of ice nuclei from measurements of ice crystals made on the spine of the Antarctic Peninsula. They found that the number of ice crystals was much larger than those predicted by the equations derived by Fletcher (1962) for mid-latitudes. However, these results were obtained for samples collected close to the surface on the Antarctic Peninsula, and may not be representative for the Antarctic atmosphere as a whole.

Identifying the source of cloud-forming nuclei can be difficult; however, two papers have looked at this problem for Antarctica. The source of ice nuclei at high southern latitudes has been investigated by Saxena \& Weintraub (1988), who found that the elements silicon, zinc and potassium, presumably combined with other elements and water, appeared to act as good ice nuclei in the filter samples taken at Palmer Station on the Antarctic 
Peninsula $\left(64^{\circ} 46^{\prime} \mathrm{S}, 64^{\circ} 03^{\prime} \mathrm{W}\right)$. Saxena (1983) has also looked at biological sources for cloud condensation nuclei. He found evidence for biogenic nuclei during flights over the Ross Ice Shelf, and he speculated that biological material from the surrounding oceans are one of the important sources for producing cloud-active aerosols.

\section{The radiative effects of clouds}

The phase, size distribution and concentration of cloud particles affect the transfer of radiation, both longwave and shortwave, through the clouds, and so clouds can have a major influence on the net radiation balance at the surface. This is true even over a high-albedo snow surface (Ambach 1974). In the Antarctic, Pavolonis \& Key (2003) have shown, using satellite data, that clouds have a warming influence on the surface over the continent in all months. Over the ocean, clouds only had a warming effect from March to October, whereas during the Antarctic summer, cloud cooled the surface. Similar results were found by Fitzpatrick \& Warren (2007) using measurements made on the RSV Aurora Australis. These results also generally compare well with in situ measurements taken at Neuymayer Station in 1993, and at the South Pole in 1986-87, with the biggest differences being found in shortwave radiation during the summer months. Of course this is to be expected, as shortwave radiation is much more sensitive to the phase, shape and size of the cloud particles, and is only important during the summer months.

Cloud radiative effects can have a large impact on the Earth's climate system by controlling the passage of radiation through the atmosphere. Climate model studies show that local cloud anomalies can have a global impact (Gordon et al. 2000). It is therefore important that clouds are correctly represented within climate models, and that local variations in cloud properties are represented. Several studies have looked at the role of Antarctic clouds within the present generation of climate models, and in particular how changes in the representation of the microphysical properties of Antarctic clouds can affect the global climate. Lubin et al. (1998) investigated the effect of ice clouds over Antarctica in the National Center for Atmospheric Research (NCAR) Community Climate Model version 2 (CCM2). They found a large difference between the modified model and the standard version of CCM2, which had water-droplet clouds both over Antarctica and in the tropics, and even in the extratropics of the Northern Hemisphere. The standard version of CCM2 has liquid cloud everywhere, and Lubin et al. (1998) used a simple modification for this that may not represent reality, although they did demonstrate the sensitivity of the atmosphere to changes in the phase of the cloud particles. Briegleb \& Bromwich (1998) investigated the polar radiation budget in the more sophisticated version 3 of the NCAR Community Climate Model (CCM3), which allows for a cloud particle ice fraction that is temperature dependant below $0^{\circ} \mathrm{C}$. However, the improved cloud microphysics did not seem to improve the radiation budget over Antarctica, and Briegleb \& Bromwich (1998) reported that the accuracy of the top of atmosphere radiation balance in CCM3, compared with Earth Radiation Budget Experiment (ERBE) data, was worse when compared with CCM2 results. Hines et al. (2004) have used used an improved progonostic cloud scheme in CCM3, but found that it was not a clear improvement over earlier schemes. Of course, one of the problems with these studies is the lack of in situ measurements in Antarctica to validate the "improved" cloud microphysical representations.

\section{Conclusions}

The isolation of Antarctica and the extreme nature of its climate mean that the study of clouds in that region is less advanced than in many other regions of the world. The surface synoptic network is on the whole more widely spaced over Antarctica, with large areas of the continent without any in situ observations. Satellite measurement of cloud parameters is also difficult over a snowy surface. This must mean that there is some doubt over the values of seasonal and area coverage of cloud given in the literature.

The few cloud microphysics measurements that have been made hint that the number of ice-forming nuclei may be several orders of magnitude greater than expected from the simple parameterization of ice nuclei number developed from mid-latitude observations (Lachlan-Cope et al. 2001), although at the moment there is no obvious source for these nuclei. Also, the work of Saxena (1983) suggests a biological source for ice nuclei, and this hints at possible complex biological feedbacks at high southern latitudes. Much more work is needed to investigate the role of cloud-forming nuclei in the Antarctic and their source, particularly as the cloud microphysics has a profound effect on the radiation balance of the atmosphere. It is therefore important to represent the cloud microphysics correctly within climate models. The present generation of cloud models use cloud parameterization developed from mid-latitude observations. However, because of the extreme environment and isolation of the Antarctic, it is unlikely that cloud observations made in other regions will be representative of Antarctica, and it is vital that in situ observations are made of Antarctic clouds in the future. 
This review of Antarctic clouds highlights both their importance and the lack of observations. It is hoped that the latest generation of meteorological satellites, carrying active instruments, will go some way to addressing this problem, but these observations must be backed up with in situ measurements made with both manned and unmanned aircraft.

\section{Acknowledgements}

The author appreciates the support of the Antarctic Meteorological Research Center, University of Wisconsin-Madison, for the satellite composite shown in Fig. 1 (Matthew Lazzara and Elena Willmot, US National Science Foundation grant numbers ANT-0537827 and ANT-0838834).

\section{References}

Ambach W. 1974. The influence of cloudiness on the net radiation balance of a snow surface with high albedo. Journal of Glaciology 13, 73-84.

Bacon N.J., Baker M.B. \& Swanson B.D. 2003. Initial stages in the morphological evolution of vapour-grown ice crystals: a laboratory investigation. Quarterly Journal of the Royal Meteorological Society 129, 1903-1927.

Briegleb B.P. \& Bromwich D.H. 1998. Polar radiation budgets of the MCAR CCM3. Journal of Climate 11, 1246-1269.

Del Guasta M., Morandi M. \& Stefanutti L. 1993. One year of cloud LIDAR data from Durmont d'Urville (Antarctica) 1. General overview of geometric and optical properties. Journal Geophysical Research-Atmospheres 98, 18 575-18 587.

Fitzpatrick M.F. \& Warren S.G. 2007. The relative importance of clouds and sea ice for the solar energy budget of the Southern Ocean. Journal of Climate 20, 941-954.

Fletcher N.H. 1962. Physics of rain clouds. Cambridge: Cambridge University Press.

Gordon C., Cooper C., Senior C.A., Banks H., Gregory J.M., Johns T.C., Mitchell J.F.B. \& Wood R.A. 2000. The simulation of SST, sea ice extents and ocean heat transports in a version of the Hadley Centre coupled model without flux adjustments. Climate Dynamics 16, 147-168.

Hahn C.J. \& Warren S.G. 2003. Cloud climatology for land stations worldwide, 1971-1996. Numerical data package NDP-026D. Oak Ridge, TN: Carbon Dioxide Information Analysis Center, US Department of Energy.

Hahn C.J., Warren S.G. \& London J. 1995. The effect of moonlight on observations of cloud cover at night, and application to cloud climatology. Journal of Climate 8, 1429-1446.

Hatzianastassiou N., Cleridou N. \& Vardavas I. 2001. Polar cloud climatologies from ISCCP C2 and D2 datasets. Journal of Climate 14, 3851-3861.
Hines K.M., Bromwich D.H., Rasch P.J. \& Iacono M.J. 2004. Antarctic clouds and radiation within the NCAR climate models. Journal of Climate 17, 1198-1212.

Hogan A.W. 1975. Summer ice crystal precipitation at the South Pole. Journal of Applied Meteorology 14, 246-249.

IPCC (Intergovernmental Panel on Climate Change) 2007. Summary for policymakers. In S. Solomon et al. (eds.): Climate change 2007. The physical science basis. Contribution of Working Group I to the fourth assessment report of the Intergovernmental Panel on Climate Change. Pp. 1-18. Cambridge: Cambridge University Press.

Kikuchi K. \& Hogan A.W. 1979. Properties of diamond dust type ice crystals observed in summer season at Amundsen-Scott South Pole Station, Antarctica. Journal of the Meteorological Society of Japan 57, 180-190.

Lachlan-Cope T., Ladkin R., Turner J. \& Davison P. 2001. Observations of cloud and precipitation particles on the Avery Plateau, Antarctic Peninsula. Antarctic Science 13, 339-348.

Lawson R.P., Baker B.A., Zmarzly P., O'Connor D., Mo Q., Gayet J. \& Shcherbakov V. 2006. Microphysical and optical properties of atmospheric ice crystals at South Pole Station. Journal of Applied Meteorology and Climatology 45, 1505-1524.

Lubin D., Chen B., Bromwich D.H., Somerville R.C.J., Lee W.-H. \& Hines K. 1998. The impact of Antarctic cloud radiative properties on a GCM climate simulation. Journal of Climate 11, 447-462.

Mahesh A., Walden V.P. \& Warren S. 2001a. Ground-based remote sensing of cloud properties over the Antarctic Plateau. Part I: cloud-base heights. Journal of Applied Meteorology 40, 1265-1278.

Mahesh A., Walden V.P. \& Warren S. 2001b. Ground-based remote sensing of cloud properties over the Antarctic Plateau. Part II: cloud optical depths and particle sizes. Journal of Applied Meteorology 40, 1279-1294.

Morley B.M., Uthe E.E. \& Viezze W. 1989. Airborne LIDAR observations of clouds in the Antarctic troposphere. Geophysical Research Letters 16, 491-494.

Ohtake T. 1978. Atmospheric ice crystals at the South Pole in summer. Antarctic Journal of the United States 13, 174-175.

Pavolonis M.J. \& Key J.R. 2003. Antarctic cloud radiative forcing at the surface estimated from the AVHRR Polar Pathfinder and ISCCP D1 datasets, 1985-93. Journal of Applied Meteorology 42, 827-840.

Rasmussen E. \& Turner J. (eds.) 2004. Polar lows: mesoscale weather systems in polar regions. Cambridge: Cambridge University Press.

Ricchiazzi P., Gautier C. \& Lubin D. 1995. Cloud scattering optical depth and local surface albedo in the Antarctic: simultaneous retrieval using ground-based radiometry. Journal of Geophysical Research-Atmospheres 100, 21 091-21 104.

Rossow W.B. \& Schiffer R.A. 1999. Advances in understanding clouds from ISCCP. Bulletin of the American Meteorological Society 80, 2261-2287. 
Saxena V.K. 1983. Evidence of the biological nuclei involvement in Antarctic coastal clouds. Journal of Physical Chemistry 87, 4130-4134.

Saxena V.K. 1996. Bursts of cloud condensation nuclei (CCN) by dissipating clouds at Palmer Station, Antarctica. Geophysical Research Letters 23, 69-72.

Saxena V.K. \& Ruggiero F.H. 1990. Antarctic coastal stratus clouds: microstructure and acidity. Antarctic Research Series $50,7-18$.

Saxena V.K. \& Weintraub D.C. 1988. Ice forming nuclei concentrations at Palmer Station, Antarctica. In P. Wagner \& G. Vali (eds.): Proceedings of the Twelfth International Conference on Atmospheric Aerosols and Nucleation, held at the University of Vienna, Austria, August 22-27, 1988. Lecture Notes in Physics 309. Pp. 679-682. Berlin: Springer.

Shimizu H. 1963. Long prism crystals observed in the precipitation in Antarctica. Journal of the Meteorological Society of Japan 41, 305-307.

Smiley V.N. 1980. LIDAR measurements in Antarctica. Antarctic Journal of the United States 15, 188-190.

Smiley V.N., Morley B.M. \& Warburton J.A. 1977. LIDAR and replication studies of the ice crystal precipitation at the South Pole. Antarctic Journal of the United States 12, 166-167.
Smiley V.N., Whitcomb B.M., Morley B.M. \& Warburton J.A. 1980. LIDAR determination of atmospheric ice crystal layers at South Pole during clear-sky precipitation Journal of Applied Meteorology 19, 1074-1090.

Spinhirne J.D., Palm S.P. \& Hart W.D. 2005. Antarctic cloud cover for October 2003 from GLAS satellite LIDAR profiling. Geophysical Research Letters, L22S05, doi: 10.1029.2005GL023782.

Stone R.S. 1993. Properties of austral winter clouds derived from radiometric profiles at the South Pole. Journal of Geophysical Research-Atmospheres 98, 12 961-12971.

Takahashi T. \& Fukata N. 1988. Ice crystal replication with common plastic solutions. Journal of Atmospheric and Ocean Technology 5, 129-135.

Town M.S., Walden V.P. \& Warren S.G. 2007. Cloud cover over the South Pole from visual observations, satellite retrievals, and surface-based infrared radiation measurements. Journal of Climate 20, 544-558.

Walden V.P., Warren S.G. \& Tuttle E. 2003. Atmospheric ice crystals over the Antarctic Plateau in winter. Journal of Applied Meteorology 42, 1391-1405.

Wang X. \& Key J.R. 2005. Arctic surface, cloud, and radiation properies based on the AVHRR Polar Pathfinder dataset. Part 1: spatial and temporal characteristics. Journal of Climate 18, 2558-2574. 